\title{
An analysis of the outcomes of totally implantable access port implantation performed by surgical residents
}

\author{
Se-Beom Jeon, Youngbae Jeon, Kyoung-Won Han, Yong-Soon Chun, Jeong-Heum Baek \\ Department of Surgery, Gil Medical Center, Gachon University College of Medicine, Incheon, Korea
}

Purpose: This study aimed to investigate the clinical outcomes after totally implantable access port (TIAP) implantation performed by general surgery residents in patients with colorectal cancer.

Methods: A total of 291 consecutive patients who underwent TIAP implantations were evaluated. The patients were divided into three groups: second-, third-, and fourth-grade residents.

Results: The mean follow-up was 22.1 months (range, 1-87 months). The total times of operation, puncture, and cannulation decreased as the resident grade increased $(P<0.001)$. Early complications significantly decreased with higher resident grades $(P=0.039)$. The non-use of ultrasonography and non-use of $\mathrm{C}$-arm were identified as independent risk factors for complications. Resident grades between second and third $(P=0.005)$ and between second and fourth $(P=0.041)$ were identified as independent risk factors for optimal tip position.

Conclusion: TIAP implantation can be safely and effectively performed by residents. Low-grade residents were associated with early complications.

Keywords: Totally implantable access ports, Resident, Complication, Risk factor

\section{INTRODUCTION}

Totally implantable access ports (TIAPs) are used in patients requiring long-term intravenous administration. It is currently used for the continuous administration of anticancer drugs. Subcutaneous insertion of access devices for chemotherapy was performed in the 1980s [1].

TIAP insertion is usually performed by a specialized surgeon or

Received: May 6, 2021 Revised: Jun 23, 2021 Accepted: Jun 28, 2021

Correspondence to: Jeong-Heum Baek

Division of Colon and Rectal Surgery, Department of Surgery, Gil Medical Center, Gachon University College of Medicine, 21 Namdong-daero

774beon-gil, Namdong-gu, Incheon 21565, Korea

Tel: +82-32-460-8428, Fax: +82-32-460-3247

E-mail: gsbaek@gilhospital.com

ORCID: Se-Beom Jeon (https://orcid.org/0000-0002-8906-4312), Youngbae Jeon (https://orcid.org/0000-0003-1322-9536), Kyoung-Won Han (https://orcid. org/0000-0001-5183-6375), Yong-Soon Chun (https://orcid.org/0000-0002-7094677X), Jeong-Heum Baek (https://orcid.org/0000-0001-9124-8041)

Copyright (C) 2021 Korean Society of Surgical Oncology

This is an Open Access article distributed under the terms of the Creative Commons Attribution Non-Commercial License (http://creativecommons.org/licenses/by-nc/4.0) which permits unrestricted non-commercial use, distribution, and reproduction in any medium, provided the original work is properly cited. an interventional radiologist. The preference for a particular procedure, such as ultrasound guidance or a blind technique for a targeted venous puncture, could differ among operators [2].

Complications such as hematoma, infection, and catheter tip malposition may occur. However, totally implantable catheter insertion is a relatively simple procedure and is safe for local anesthesia [3-5]. Therefore, it is a common practice in university hospitals as part of the training process. Several studies have compared the safety of the procedure between staff and residents and among different vascular access routes performed by residents [6,7]. However, there has been no report on the safety and effectiveness of successful TIAP implantations among different resident grades.

This study aimed to retrospectively investigate the long-term safety and effectiveness of TIAP implantation performed by three different resident groups (second-, third-, and fourth-grade residents) for educational purposes.

\section{METHODS}

Patient selection and resident groups

A total of 345 patients with high-risk or stage IV colorectal cancer underwent TIAP implantations from January 2013 to December 


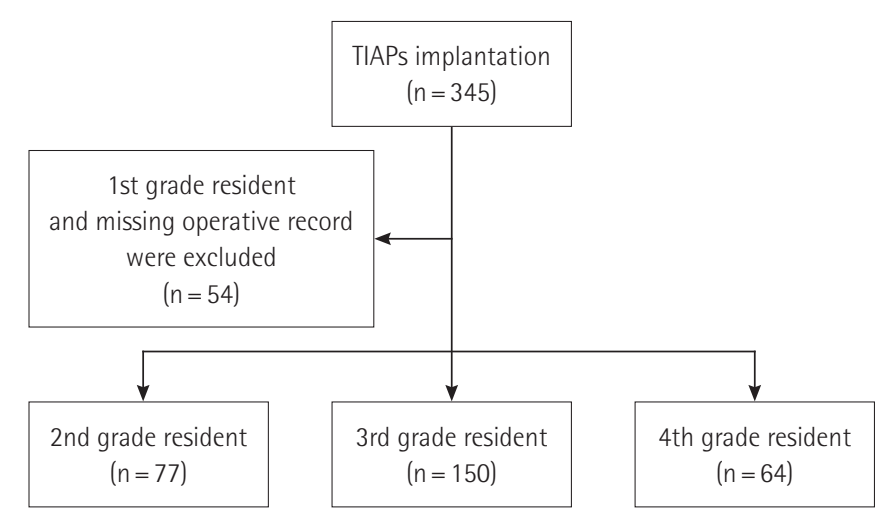

Fig. 1. Study flowchart. TIAP, totally implantable access port.

2015 in the Department of Surgery, Gachon University Gil Medical Center. All chemoport insertions were performed by trainee-residents in the department of surgery. The patients were divided into three groups according to the grade of the resident who performed the implantation: second, third, and fourth grade. All residents were trained on five cases of TIAPs under the observation of the staff before the 1st TIAPs. Fifty-four patients were excluded from the analysis because TIAP implantation was performed by a first-grade (inexperienced) resident and because of incomplete data in the operation record. Finally, 291 consecutive patients were retrospectively included in this study (Fig. 1). All relevant data were entered into a prospectively maintained database. Our practice is to follow up colorectal cancer patients every 3 months postoperatively for the first 2-3 years, and every 6 months thereafter up to 5 years. TIAPs were removed when adjuvant chemotherapy was completed or when problems with the chemoport, such as infection or malfunction, occurred. TIAPs were maintained in stage IV patients for continued chemotherapy. This study was approved by the Institutional Review Board of Gachon University Gil Medical Center (IRB No. GAIRB2020-332). The informed consent was waived.

\section{Assessment parameters}

Baseline patient characteristics including age, sex, body mass index (BMI), insertion route, postoperative complications, lead time for implantation, and catheter tip position were evaluated. We investigated the long-term follow-up for catheter maintenance, and the median follow-up duration was defined as the period from the month when TIAP implantations were performed to the last follow-up month.

\section{Procedure for port implantation}

The TIAP procedure was performed in the operating room under local anesthesia. All TIAP implantations were performed via inter- nal jugular vein (IJV) puncture. If the patient had undergone right breast surgery before port implantation or had unfavorable vascular anatomy, the left IJV was used. The chemoport catheter was implanted using the Seldinger technique because it was more effective and quicker than the cut-down technique [8]. The catheter placement was confirmed with postoperative radiography.

\section{Complications}

Complications were analyzed as early complications or late complications. Early complications were defined as complications that occurred within a week after surgery, and classified as bleeding, puncture failure, reposition, reinsertion, and pneumothorax. Bleeding was defined as having more than $5 \mathrm{~mL}$ of extra blood loss during surgery. And puncture failure was defined as attempting to puncture IJV two or more times. Late complications included infection, obstruction, thrombosis, and catheter injury. Infection was defined as removal of TIAPs because of local infection. The incidence of thrombosis was confirmed using follow-up computed tomography.

\section{Evaluation of successful TIAP implantation}

The catheter tip position is an important indicator of whether TIAP implantations have been performed properly. Although the optimal tip position is controversial, it is generally known that the position between the superior vena cava and right atrium junctions is appropriate $[9,10]$. We measured the vertebral body units (VBU) by checking the chest radiograph after surgery as a method to determine the optimal position of the catheter tip [11]. Taking into account the measurement error in chest radiography, 0-2.5 $\mathrm{VBU}$ was defined as optimal tip positioning, and $\mathrm{VBU}<0$ or $\mathrm{VBU}$ $>2.5$ was defined as malpositioning $[11,12]$.

\section{Statistical analysis}

Statistical analysis was performed using SPSS 23.0 (IBM Corp., Armonk, NY, USA). To analyze the variables affecting the clinical characteristics, operative outcome, and complications of patients, the resident group was used as a factor variable (independent variable). The dependent variables were divided into discontinuous and continuous variables. Noncontinuous variables were analyzed using chi-square cross analysis, and continuous variables were analyzed using one-way analysis of variance.

Sex, age, tip position, VBU, and puncture time were compared using Scheffe test, assuming uniform variance. The Tamhane test was used for route, ultrasonography (USG) use, C-arm use, cannulation time, total operation time, and complications because these variables did not assume equal variance. Logistic regression analysis was performed to analyze the risk factors affecting compli- 
cations and optimal tip positions. Sex, age, BMI, route, USG use, $\mathrm{C}$-arm use, and resident group were used as variables for univariate analysis, and multivariate analysis was performed by selecting variables with a P-value of $<0.05$. The catheter maintenance period was analyzed using the Kaplan-Meier method and log-rank test.

\section{RESULTS}

The clinical characteristics of patients among the resident-grade groups are shown in Table 1. A total 291 TIAP implantations were performed: second-grade residents $(\mathrm{n}=77)$, third-grade residents $(\mathrm{n}=150)$, and fourth-grade residents $(\mathrm{n}=64)$. No statistically significant differences were observed among the groups in age, sex, and BMI. All TIAP implantations were performed via the IJV: 285 patients underwent implantation via the right IJV, and six patients underwent implantation via the left IJV. The route was also not significantly different among the resident-grade groups. However, differences were observed among the three groups in the use of USG and C-arm. The higher the grade, the lower the frequency of USG use $(\mathrm{P}<0.001)$, whereas the $\mathrm{C}$-arm use was the same $(\mathrm{P}=$ $0.015)$

The comparison of operative outcomes and complications according to the grade of residents is shown in Table 2. The puncture time was shorter when the resident grade was higher $(\mathrm{P}=0.033)$. The cannulation time and total operation time were also shorter as the resident grade became higher, and the differences were signifi- cant $(\mathrm{P}<0.001)$.

The VBU, calculated as an indicator for a successful TIAP implantation, was more frequently in the proper range in lower resident grades; however, there was no significant difference among the groups $(\mathrm{P}=0.080)$.

Fifty-four early complications (18.6\%) occurred in the 291 TIAP implantations. Early complications decreased with higher resident grades and were statistically significant $(\mathrm{P}=0.039)$. The most frequently documented early complication was bleeding at the insertion site, which showed statistically significant differences among the resident groups. Two simple chest radiographs were examined after TIAP implantations in all 291 patients, but pneumothorax was not detected.

Late complications were confirmed in 18 cases (6.2\%); however, there was no significant difference among the resident groups. All late complications were not statistically different among the resident groups.

All possible risk factors for early complications were evaluated using univariate analysis (Table 3). Univariate analysis showed that the use of USG (odds ratio [OR], 0.41; 95\% confidence interval [CI], 0.17-1.02; $\mathrm{P}=0.055)$, use of C-arm (OR, 0.43; 95\% CI, 0.24$0.79 ; \mathrm{P}=0.007$ ), and TIAP implantations performed by thirdgrade residents compared with second-grade residents (OR, 0.33; $95 \% \mathrm{CI}, 0.13-0.83 ; \mathrm{P}=0.019)$ were associated with a decreased incidence of complications. Multivariate analysis also showed that the none use of USG (OR, 0.31; 95\% CI, $0.12-0.82 ; \mathrm{P}=0.018)$ and

Table 1. Clinical characteristics of patients among the resident-grade groups

\begin{tabular}{|c|c|c|c|c|c|}
\hline Characteristics & Total $(n=291)$ & $2 G(n=77)$ & $3 G(n=150)$ & $4 G(n=64)$ & P-value \\
\hline Age (yr) & $58.7 \pm 11.2$ & $61.1 \pm 10.0$ & $57.8 \pm 11.4$ & $58.1 \pm 11.6$ & 0.870 \\
\hline Sex & & & & & 0.366 \\
\hline Male & $168(55.7)$ & 46 (59.7) & $90(60.0)$ & $32(50.0)$ & \\
\hline Female & $123(42.3)$ & $31(40.3)$ & $60(40.0)$ & $32(50.0)$ & \\
\hline $\mathrm{BMI}$ & & & & & 0.205 \\
\hline$<25 \mathrm{~kg} / \mathrm{m}^{2}$ & $216(74.2)$ & $59(76.6)$ & 115 (76.7) & $42(65.6)$ & \\
\hline$\geq 25 \mathrm{~kg} / \mathrm{m}^{2}$ & 75 (25.8) & $18(23.4)$ & 35 (23.3) & $22(34.4)$ & \\
\hline Route & & & & & 0.214 \\
\hline Left IJV & $6(2.1)$ & $3(3.9)$ & $1(0.7)$ & 2 (3.1) & \\
\hline Right IJV & 285 (97.9) & 74 (96.1) & 149 (99.3) & 62 (96.9) & \\
\hline USG & & & & & $<0.001$ \\
\hline Used & $230(79.0)$ & 73 (94.8) & $102(68.0)$ & 55 (85.9) & \\
\hline Not used & 61 (21.0) & $4(5.2)$ & 48 (32.0) & $9(14.1)$ & \\
\hline C-arm & & & & & 0.015 \\
\hline Used & 94 (32.3) & 32 (41.6) & $50(33.3)$ & 12 (18.8) & \\
\hline Not used & 197 (67.7) & 45 (58.4) & $100(66.7)$ & 52 (81.2) & \\
\hline
\end{tabular}

Values are presented as mean \pm standard deviation or number (\%).

2G, second-grade resident group; 3G, third-grade resident group; 4G, fourth-grade resident group; BMI, body mass index; IJV, internal jugular vein; USG, ultrasonography. 
Table 2. Operative outcomes, complications, and median follow-up duration according to resident grade

\begin{tabular}{|c|c|c|c|c|c|}
\hline Characteristics & Total $(n=291)$ & $2 G(n=77)$ & $3 G(n=150)$ & $4 G(n=64)$ & P-value \\
\hline Tip position (cm) & $3.8 \pm 2.5$ & $2.9 \pm 2.2$ & $4.2 \pm 2.6$ & $3.8 \pm 2.5$ & 0.001 \\
\hline Puncture time (min) & $3.5 \pm 3.3$ & $4.1 \pm 2.3$ & $3.5 \pm 3.9$ & $2.7 \pm 2.6$ & 0.033 \\
\hline Cannulation time (min) & $9.5 \pm 7.8$ & $14.1 \pm 9.8$ & $8.3 \pm 6.7$ & $6.5 \pm 4.3$ & $<0.001$ \\
\hline Total time (min) & $34.1 \pm 10.5$ & $41.3 \pm 11.3$ & $32.3 \pm 9.2$ & $29.7 \pm 8.0$ & $<0.001$ \\
\hline VBU & & & & & 0.080 \\
\hline $0-2.5$ & 234 (80.4) & $57(74.0)$ & $95(63.3)$ & $36(56.2)$ & \\
\hline$<0$ or $>2.5$ & 57 (19.6) & $20(26.0)$ & $55(36.6)$ & $28(43.8)$ & \\
\hline \multicolumn{6}{|l|}{ Complications } \\
\hline Early complications & $54(18.6)$ & $21(27.3)$ & $26(17.3)$ & $7(10.9)$ & 0.039 \\
\hline Bleeding & & $16(20.8)$ & $16(10.7)$ & $3(4.7)$ & 0.011 \\
\hline Puncture failure & & $1(1.3)$ & $8(5.3)$ & $2(3.1)$ & 0.305 \\
\hline Reposition & & $1(1.3)$ & 0 & 0 & 0.248 \\
\hline Reinsertion & & $3(3.9)$ & $1(0.7)$ & $2(3.1)$ & 0.214 \\
\hline Pneumothorax & & 0 & 0 & 0 & \\
\hline Late complications & $18(6.2)$ & $4(5.2)$ & $12(8.0)$ & $2(3.1)$ & 0.365 \\
\hline Infection & & $2(2.6)$ & $4(2.7)$ & 0 & 0.421 \\
\hline Obstruction & & $1(1.3)$ & $5(3.3)$ & $1(1.6)$ & 0.564 \\
\hline Thrombosis & & $1(1.3)$ & $1(0.6)$ & $1(1.6)$ & 0.808 \\
\hline Catheter injury & & 0 & $1(0.6)$ & 0 & 0.624 \\
\hline Follow-up duration (mo) & $17(1-81)$ & $19(1-62)$ & $15(1-81)$ & $18(3-69)$ & 0.533 \\
\hline
\end{tabular}

Values are presented as mean \pm standard deviation, number (\%), or median (range).

2G, second-grade resident group; 3G, third-grade resident group; 4G, fourth-grade resident group; VBU, vertebral body units.

Table 3. Univariate and multivariate analyses for risk factors of early complications

\begin{tabular}{|c|c|c|c|c|}
\hline \multirow{2}{*}{ Factor } & \multicolumn{2}{|c|}{ Univariate analysis } & \multicolumn{2}{|c|}{ Multivariate analysis } \\
\hline & OR $(95 \% \mathrm{Cl})$ & P-value & OR $(95 \% \mathrm{Cl})$ & P-value \\
\hline Sex (female/male) & $0.75(0.41-1.35)$ & 0.333 & & \\
\hline Age (> 58 yr) & $0.79(0.44-1.44)$ & 0.445 & & \\
\hline $\mathrm{BMI}\left(\leq 25 \mathrm{~kg} / \mathrm{m}^{2}\right)$ & 1.76 (0.93-3.31) & 0.082 & & \\
\hline Side (left/right) & $2.24(0.40-12.60)$ & 0.359 & & \\
\hline USG (yes/no) & $0.41(0.17-1.02)$ & 0.055 & $0.31(0.12-0.82)$ & 0.018 \\
\hline C-arm (yes/no) & $0.43(0.24-0.79)$ & 0.007 & $0.38(0.20-0.72)$ & 0.003 \\
\hline \multicolumn{5}{|l|}{ Resident grade } \\
\hline $2 \mathrm{G}$ & 1 & & & \\
\hline $3 G$ & $0.33(0.13-0.83)$ & 0.019 & $0.45(0.17-1.18)$ & 0.105 \\
\hline $4 \mathrm{G}$ & $0.59(0.24-1.43)$ & 0.240 & & \\
\hline
\end{tabular}

$\mathrm{OR}$, odds ratio; $\mathrm{Cl}$, confidence interval; $\mathrm{BMI}$, body mass index; USG, ultrasonography; $2 \mathrm{G}$, second-grade resident group; $3 \mathrm{G}$, third-grade resident group; $4 \mathrm{G}$, fourth-grade resident group.

use of C-arm (OR, 0.38; 95\% CI, 0.20-0.72; P=0.003) were independent risk factors for complications.

The possible risk factors for late complications were also evaluated using univariate analysis (Table 4). C-arm use (OR, 0.36; 95\% CI, 0.14-0.93; $\mathrm{P}=0.036$ ) was the only independent risk factor for late complications.

We analyzed the variables affecting the catheter maintenance period. The duration of the catheter maintenance period was not significantly different according to resident groups and early complications (Figs. 2, 3). However, the catheter maintenance period was different depending on late complications ( $\mathrm{P}=0.003$ ) (Fig. 4).

We also evaluated the risk factors of optimal tip position with univariate analysis (Table 5). The use of C-arm (OR, 2.02; 95\% CI, 1.01-4.04; $\mathrm{P}=0.046$ ), TIAP implantations performed by thirdgrade residents compared with second-grade residents (OR, 0.26; 95\% CI, 0.10-0.64; $\mathrm{P}=0.004$ ), and TIAP implantations performed 
Table 4. Univariate and multivariate analyses for risk factors of late complications

\begin{tabular}{|c|c|c|c|c|}
\hline \multirow{2}{*}{ Factor } & \multicolumn{2}{|c|}{ Univariate analysis } & \multicolumn{2}{|c|}{ Multivariate analysis } \\
\hline & OR $(95 \% \mathrm{Cl})$ & P-value & OR $(95 \% \mathrm{Cl})$ & P-value \\
\hline Sex (female/male) & $2.26(0.85-6.01)$ & 0.102 & & \\
\hline Age (> 58 yr) & $1.22(0.47-3.19)$ & 0.681 & & \\
\hline BMI $\left(\leq 25 \mathrm{~kg} / \mathrm{m}^{2}\right)$ & $1.48(0.54-4.10)$ & 0.451 & & \\
\hline Side (left/right) & $3.15(0.35-28.52)$ & 0.307 & & \\
\hline USG (yes/no) & $1.08(0.34-3.42)$ & 0.892 & & \\
\hline C-arm (yes/no) & $0.36(0.14-0.93)$ & 0.036 & & \\
\hline \multicolumn{5}{|l|}{ Resident grade } \\
\hline $2 \mathrm{G}$ & 1 & & & \\
\hline $3 G$ & $0.59(0.10-3.32)$ & 0.549 & & \\
\hline $4 \mathrm{G}$ & $0.37(0.08-1.70)$ & 0.203 & & \\
\hline
\end{tabular}

$\mathrm{OR}$, odds ratio; $\mathrm{Cl}$, confidence interval; $\mathrm{BMI}$, body mass index; USG, ultrasonography; 2G, second-grade resident group; 3G, third-grade resident group; 4G, fourth-grade resident group.

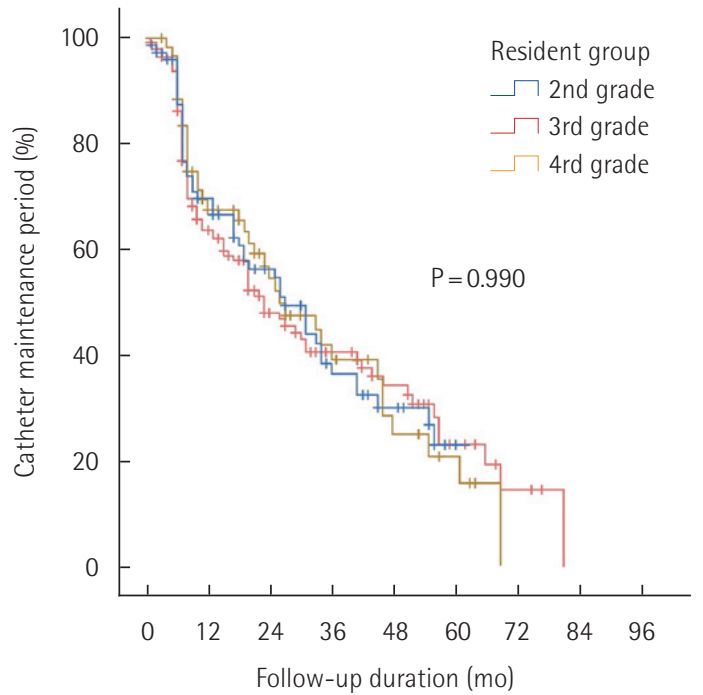

Fig. 2. Kaplan-Meier survival test of the catheter maintenance period by resident group.

by fourth-grade residents compared with second-grade residents (OR, 0.30; 95\% CI, 0.10-0.84; $\mathrm{P}=0.022$ ) were significant risk factors for optimal tip position. In multivariate analysis, the use of C-arm (OR, 1.90; 95\% CI, 0.94-3.86; $\mathrm{P}=0.075)$ was not a significant independent risk factor. However, resident grade between second and third (OR, 0.27; 95\% CI, 0.11-0.67; $\mathrm{P}=0.005)$ and between second and fourth (OR, $0.34 ; 95 \% \mathrm{CI}, 0.12-0.96 ; \mathrm{P}=0.041)$ were independent risk factors for optimal tip position.

\section{DISCUSSION}

TIAP implantation is important for long-term safe venous access in patients with malignant tumors. A large number of TIAP im-

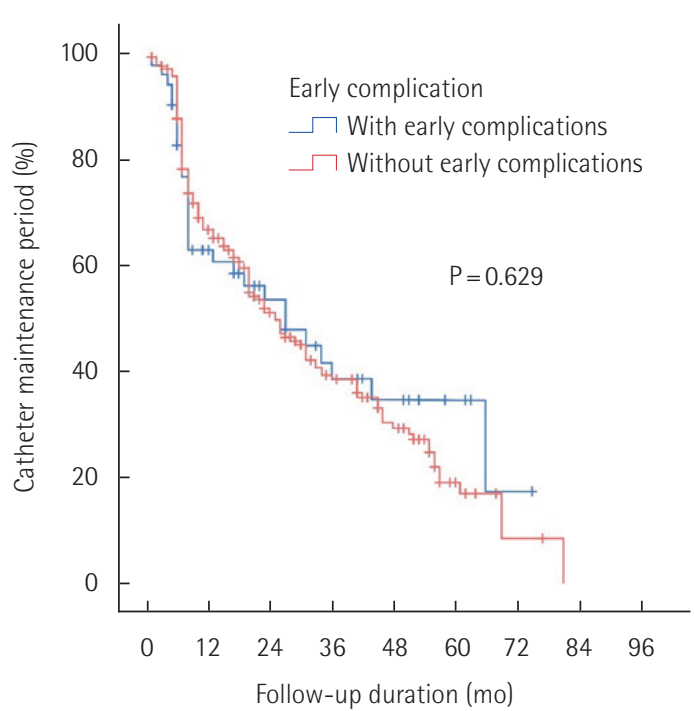

Fig. 3. Kaplan-Meier survival test of the catheter maintenance period by early complications.

plantations have been applied in many hospitals because of the increasing use of chemoports for the chemotherapy of malignant tumors. In the past, TIAP implantation was performed by a specialized surgeon or radiologist; however, it is now a basic surgical technique for resident training and has been confirmed to be safe even when performed by a surgical resident in previous studies [6]. However, considering the reduction of complications and the importance of successful TIAP implantations, the timing of appropriate training should be given consideration.

As most TIAP implantations are performed under local anesthesia, shortening the operation time is important for reducing the patients' physical and mental pain. In previous studies on TIAP implantations performed by residents, the mean total operation 
Table 5. Univariate and multivariate analyses for risk factors of optimal tip position

\begin{tabular}{|c|c|c|c|c|}
\hline \multirow{2}{*}{ Factor } & \multicolumn{2}{|c|}{ Univariate analysis } & \multicolumn{2}{|c|}{ Multivariate analysis } \\
\hline & OR (95\% Cl) & P-value & OR $(95 \% \mathrm{Cl})$ & P-value \\
\hline Sex (female/male) & $1.01(0.56-1.81)$ & 0.978 & & \\
\hline Age (> $58 \mathrm{yr}$ ) & $1.70(0.94-3.05)$ & 0.079 & & \\
\hline $\mathrm{BMI}\left(\leq 25 \mathrm{~kg} / \mathrm{m}^{2}\right)$ & $2.10(0.97-4.51)$ & 0.059 & & \\
\hline Side (left/right) & $0.23(0.05-1.20)$ & 0.080 & & \\
\hline USG (yes/no) & $0.47(0.20-1.09)$ & 0.078 & & \\
\hline C-arm (yes/no) & $2.02(1.01-4.04)$ & 0.046 & $1.90(0.94-3.86)$ & 0.075 \\
\hline \multicolumn{5}{|l|}{ Resident grade } \\
\hline $2 \mathrm{G}$ & 1 & & & \\
\hline $3 G$ & $0.26(0.10-0.64)$ & 0.004 & $0.27(0.11-0.67)$ & 0.005 \\
\hline $4 \mathrm{G}$ & $0.30(0.10-0.84)$ & 0.022 & $0.34(0.12-0.96)$ & 0.041 \\
\hline
\end{tabular}

$\mathrm{OR}$, odds ratio; $\mathrm{Cl}$, confidence interval; $\mathrm{BMI}$, body mass index; USG, ultrasonography; $2 \mathrm{G}$, second-grade resident group; $3 \mathrm{G}$, third-grade resident group; 4G, fourth-grade resident group.

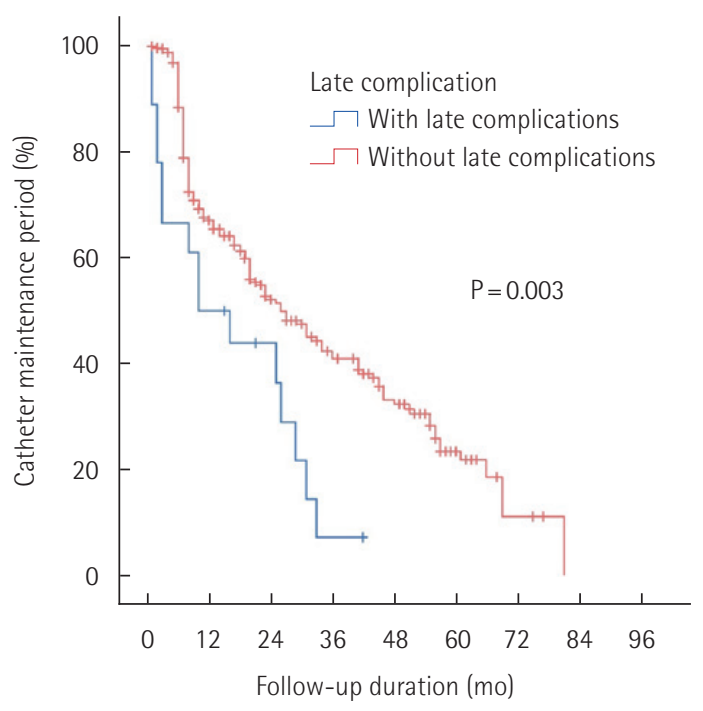

Fig. 4. Kaplan-Meier survival test of the catheter maintenance period by late complications.

time of the resident group was 33-46 minutes [6,7]. The total operation time in our study was $34.1 \pm 10.5$ minutes, which is comparable to the results of other previously published studies. In this study, it was confirmed that the operation time was significantly shorter as the resident grade increased. Moreover, it was confirmed that the operation time was significantly shorter as the grade increased. Although we did not conduct an analysis of the learning curve, the results can indirectly show the difference in the cumulative experience with the TIAP procedure.

TIAP implantation can have a variety of complications, from relatively insignificant complications such as bleeding or puncture failure to important complications including infections or thrombosis. The intraoperative complication rate in other studies on TIAP implantations performed by residents alone was $2.2 \%$, which was lower than that in our study. However, in a previous study, bleeding was not included as a complication [6]. If bleeding is to be excluded from complications, then there would be no significant difference from the early complication rate in our study (6.5\%). Conversely, the late complication rate in our study (6.2\%) was lower than the postoperative complication rate in the previous study (15.7\%) [6]. In our study, the decrease in the incidence of early complications as the resident grade became higher indicates that it is important that the operation is performed by higher-grade residents. However, considering that most complications are minor complications such as bleeding, and there was no statistical difference in critical complications, including puncture failure, reinsertion, and late complications, the procedure can be considered relatively safe even if performed by a low-grade resident.

The use of USG in TIAP implantation is important for safe venous catheterization. This is known as a method to avoid problems such as arterial puncture and puncture failure $[13,14]$. In this study, fewer complications occurred when USG and C-arm were used and performed by third-grade residents rather than second-grade residents. However, the complication ratio between the second-grade resident group and the fourth-grade resident group was not statistically significant, which means that the use of USG and $\mathrm{C}$-arm is more important than the resident grade in TIAP implantation.

One of the objectives of this study was to analyze the factors affecting catheter maintenance through a long-term follow-up of TIAP implantations. Considering that late complications are an important factor in catheter maintenance, it can be presumed that the management of chemoports is more important than the grade of the resident performing TIAP implantation.

In addition, a C-arm is used to place the catheter in the proper position [15], which is important considering that malpositioning 
of the catheter may cause serious complications such as central venous thrombosis and cardiac tamponade [16,17]. According to the results of this study, proper catheter positioning according to the use of C-arm was statistically significant. However, the tip position was inadequate as the resident grade became higher. Considering that the frequency of $\mathrm{C}$-arm use decreased as the resident grade increased, this means that the use of C-arm is more important than the procedural experience and is a major factor in determining the optimal location of the catheter. The conclusion of the study support the use of ultrasound and C-arm during the procedure to reduce complication risk even in low-grade residents.

This study had some limitations. First, it had a retrospective design, which could lead to a selection bias. Second, we did not perform learning curve analysis. Although there were significant differences in operative time and early complications according to the resident grade, the exact number of chemoport insertion procedures each resident has performed was unclear. However, this study is meaningful in that it analyzed the important factors for a successful chemoport catheter implantation, which is one of the basic procedures for general surgery resident training, over a longterm period.

In conclusion, Taking into consideration the operation time and complications, it would be appropriate for TIAP implantations to be performed by third- or fourth-grade residents. However, considering that it can be sufficiently performed properly with the use of USG and C-arm, TIAP implantation can be safely and effectively performed even by low-grade residents.

\section{CONFLICT OF INTEREST}

No potential conflict of interest relevant to this article was reported.

\section{ACKNOWLEDGMENTS}

Conceptualization: SBJ, YSJ, JHB. Formal Analysis: SBJ. Investigation: SBJ. Methodology: SBJ, YJ, KWH, JHB. Project administration: JHB, YSJ. Writing - original draft: SBJ, YJ. Writing - review \& editing: SBJ, YJ, KWH, YSJ, JHB.

\section{REFERENCES}

1. Niederhuber JE, Ensminger W, Gyves JW, Liepman M, Doan K, Cozzi E. Totally implanted venous and arterial access system to replace external catheters in cancer treatment. Surgery 1982;92:70612.

2. An H, Ryu CG, Jung EJ, Kang HJ, Paik JH, Yang JH, et al. Insertion of totally implantable central venous access devices by surgeons.
Ann Coloproctol 2015;31:63-7.

3. Inaba Y, Yamaura H, Sato Y, Najima M, Shimamoto H, Nishiofuku $\mathrm{H}$, et al. Central venous access port-related complications in outpatient chemotherapy for colorectal cancer. Jpn J Clin Oncol 2007;37: 951-4.

4. Kurul S, Saip P, Aydin T. Totally implantable venous-access ports: local problems and extravasation injury. Lancet Oncol 2002;3:68492.

5. Voog E, Campion L, du Rusquec P, Bourgeois H, Domont J, Denis F, et al. Totally implantable venous access ports: a prospective longterm study of early and late complications in adult patients with cancer. Support Care Cancer 2018;26:81-9.

6. Schreckenbach T, Munch I, El Youzouri H, Bechstein WO, Habbe $\mathrm{N}$. The safety level of total central venous access port implantation performed by residents. J Surg Educ 2019;76:182-92.

7. Matsushima H, Adachi T, Iwata T, Hamada T, Moriuchi H, Yamashita $\mathrm{M}$, et al. Analysis of the outcomes in central venous access port implantation performed by residents via the internal jugular vein and subclavian vein. J Surg Educ 2017;74:443-9.

8. Nocito A, Wildi S, Rufibach K, Clavien PA, Weber M. Randomized clinical trial comparing venous cutdown with the Seldinger technique for placement of implantable venous access ports. Br J Surg 2009;96:1129-34.

9. McGee WT, Ackerman BL, Rouben LR, Prasad VM, Bandi V, Mallory DL. Accurate placement of central venous catheters: a prospective, randomized, multicenter trial. Crit Care Med 1993;21: 1118-23.

10. Fletcher SI, Bodenham AR. Safe placement of central venous catheters: where should the tip of the catheter lie? Br J Anaesth 2000;85: 188-91.

11. Song YG, Byun JH, Hwang SY, Kim CW, Shim SG. Use of vertebral body units to locate the cavoatrial junction for optimum central venous catheter tip positioning. Br J Anaesth 2015;115:252-7.

12. Schuster M, Nave H, Piepenbrock S, Pabst R, Panning B. The carina as a landmark in central venous catheter placement. Br J Anaesth 2000;85:192-4.

13. Zhou J, Qian S, He W, Han G, Li H, Luo R. Implanting totally implantable venous access port via the internal jugular vein guided by ultrasonography is feasible and safe in patients with breast cancer. World J Surg Oncol 2014;12:378.

14. Dolu H, Goksu S, Sahin L, Ozen O, Eken L. Comparison of an ultrasound-guided technique versus a landmark-guided technique for internal jugular vein cannulation. J Clin Monit Comput 2015; 29:177-82.

15. Chaudhary M, Idowu O, Kim S. A method to accurately estimate the catheter length needed for a tunneled central catheter placement. Pediatr Surg Int 2018;34:693-6. 
16. Tanioka H, Asano M, Kawasaki K, Yoshida R, Waki N, Uno F, et al. Incidence of catheter-related thrombosis in patients with longterm indwelling central venous port who received chemotherapies for unresectable advanced digestive cancers. Gan To Kagaku Ryo- ho 2019;46:2182-4.

17. Defalque RJ, Campbell C. Cardiac tamponade from central venous catheters. Anesthesiology 1979;50:249-52. 